\title{
CRH Signalling in the Bed Nucleus of the Stria Terminalis is Involved in Stress-Induced Cardiac Vagal Activation in Conscious Rats
}

\author{
Marjoleen J.M.A. Nijsen, Ph.D., Gerda Croiset, M.D., Ph.D., Michaela Diamant, , M.D., Ph.D., \\ David De Wied, , M.D., Ph.D., and Victor M. Wiegant, Ph.D.
}

The bed nucleus of the stria terminalis (BNST) is involved in autonomic and behavioral reactions to fearful stimuli and contains corticotropin-releasing hormone (CRH) fibers and terminals. The role of $C R H$ in the medial part of the BNST in the regulation of heart rate (HR) and $P Q$ interval of the electrocardiogram was studied under resting conditions and conditioned fear stress in freely moving rats. Microinfusion of CRH $(0.2 \mu \mathrm{g} / 0.6 \mu \mathrm{l})$ in the medial BNST under resting conditions significantly enhanced $H R$ as compared to saline treatment, but did not reduce the $P Q$ interval, indicating that exogenous CRH in the medial BNST can activate both the sympathetic and parasympathetic cardiac outflow. In addition, CRH induced a slight increase in gross locomotor activity, an effect that succeeded the tachycardiac response, indicating that the HR response was not a consequence of increased locomotor activity, but likely a direct effect of CRH. CF was induced by 10-min forced exposure to a cage in which the rat had experienced footshocks $(5 \times 0.5 \mathrm{~mA} \times$ 3s) the day before. $\alpha$-helical CRH(9-41) ( $\alpha h C R H ; 5 \mu \mathrm{g} / 0.6$ $\mu l)$, a non-selective $C R H$ receptor antagonist, or saline was infused into the medial BNST of rats prior to CF. CF induced freezing behavior, associated with an increase in $H R$ and $P Q$ interval, indicating activation of sympathetic and vagal outflow to the heart. $\alpha$ hCRH significantly reduced the $P Q$ response, but enhanced the tachycardia, suggesting inhibition of vagal activity. In addition, $\alpha$ helical CRH(9-41) reduced the freezing response. Taken together, the data provide first evidence that $\mathrm{CRH}$, released in the medial BNST during stress, contributes to cardiac stress responses, particularly by activating vagal outflow. [Neuropsychopharmacology 24:1-10, 2001] (C) 2000 American College of Neuropsychopharmacology. Published by Elsevier Science Inc. All rights reserved.
KEY WORDS: Corticotropin-releasing factor;

\section{Electrocardiogram; Autonomic nervous system; Behavior}

The bed nucleus of the stria terminalis (BNST) is a rostral forebrain structure that is enclosed by the lateral ventri-

From the Rudolf Magnus Institute for Neurosciences, Department of Medical Pharmacology, Utrecht University, Utrecht, The Netherlands (MJMAN, GC, DDW, VMW); and Department of Endocrinology and Metabolic Diseases, Leiden University Medical Centre, Leiden, The Netherlands (MD).

Address correspondence to: Dr. M.J.M.A. Nijsen, Rudolf Magnus Institute for Neurosciences, Department of Medical Pharmacology, P.O. Box 80040, 3508 TA Utrecht, The Netherlands.

Received 19 November 1999; revised 25 May 2000; accepted 31 May 2000. cle, lateral septum, fornix, nucleus accumbens, preoptic area and hypothalamus. The BNST has been recognized as an important relay station which links the amygdala and hippocampus with the paraventricular hypothalamic nucleus (PVN) and brain stem regions (Herman et al. 1994; Pacak et al. 1995; Davis et al. 1997). Projections have been found from the BNST to autonomic regulatory brain stem areas: the nucleus tractus solitarius (NTS) (Holstege et al. 1985; Gray and Magnuson 1987), caudal ventrolateral medulla (CVLM) (Giancola et al. 1993), and dorsal nucleus of the vagus (DMV) (Gray and Magnuson 1987; Hopkins 1987), supporting the role of the BNST in the regulation of autonomic responses.

Its rich connections with the amygdala and PVN sug- 
gest that the BNST is involved in the stress response. Indeed, it has been reported that restraint stress induces cfos expression in the BNST in rats (Arnold et al. 1992; Bonaz and Tache 1994). In addition, Onaka and Yagi (1998) reported that conditioned fear activates noradrenergic projections to the BNST in rats as depletion of the norepinephrine content of the BNST by 5-amino-2,4dihydroxy-alpha-methylphenylethylamine, a neurotoxin, impaired the conditioned fear-induced behavioral response. The potential importance of the BNST in the stress response is further reflected by projections of the perifornical area of the hypothalamus to the BNST (Allen and Cechetto 1993). Stimulation of this hypothalamic area mimics stress-induced neuroendocrine and autonomic responses, i.e. elevation of blood pressure (BP), heart rate (HR), plasma norepinephrine, and epinephrine (Allen and Cechetto 1993; Stoddard et al. 1986a,b).

Corticotropin-releasing hormone (CRH) acts within the central nervous system (CNS) to mediate behavioral, autonomic and hormonal responses to stress (Koob et al. 1989; Fisher 1993; Song et al. 1995). CRHcontaining fibbers have been found in the BNST (Swanson et al. 1983; Valentino and Foote 1986; Phelix and Paull 1990) and CRH-containing terminals, arising from the amygdala, have been detected in the dorsolateral BNST (Sakanaka et al. 1986). Arnold and colleagues (1992) reported that restraint stress-induced c-fos expression in the medial BNST can be blocked by intracerebroventricular (icv) injection of $\alpha$-helical CRH(9-41) $(\alpha \mathrm{hCRH})$, a non-selective $\mathrm{CRH} 1$ and $\mathrm{CRH} 2$ receptor antagonist, in rats. Furthermore, they demonstrated that icv injection of $\mathrm{CRH}$ induces c-fos expression in the medial BNST, similar to that found after restraint stress. Others determined the concentration of CRH-like immunoreactivity in the BNST by combined radioimmunoassay-micropunch dissection techniques and found that it was increased by acute or chronic stress (Chappell et al. 1986). Taken together, these findings suggest that stress activates the CRH system in the BNST. There is evidence for the involvement of the BNST in CRHmediated behavioral stress responses. Lee and Davis (1997) demonstrated that CRH infusion into the medial and dorsolateral BNST in rats enhanced the fear-potentiated startle response. This CRH-effect could be blocked by $\alpha \mathrm{hCRH}$, suggesting that endogenous CRH binds to $\mathrm{CRH}$ receptors in the medial and dorsolateral BNST to induce anxiogenic-like behavior during stress. Indeed, $\mathrm{CRH}$ type 1 receptors have been found in the medial and lateral BNST, whereas the type 2 receptor has been localized in the medial BNST (Chalmers et al. 1995).

So far, however, CRH signalling in the BNST has not been directly related to autonomic stress responses. Previously, we have demonstrated that icv infused $\mathrm{CRH}$ activates both the sympathetic and vagal cardiac system in conscious rats under resting conditions (Nijsen et al. 2000b). Conversely, in another study, we blocked the endogenous CRH system by icv infusion of $\alpha \mathrm{hCRH}$ prior to conditioned fear and showed that endogenous CRH inhibits emotional stress-induced vagal cardiac activation (Nijsen et al. 2000a). The question remained which brain regions are involved in these $\mathrm{CRH}$-induced autonomic responses.

Therefore, the aim of this study was to examine the role of CRH activity in the medial BNST in autonomic responses to emotional stress. To that end, rats were infused with CRH in the medial BNST under resting conditions, or with $\alpha \mathrm{hCRH}$ prior to conditioned fear, that is stress induced by forced exposure to an environment in which rats previously experienced inescapable footshocks. The sympathetic and vagal cardiac effects were investigated by using HR in combination with the PQ interval of the electrocardiogram (ECG), both indices of the sympathovagal balance (Croiset et al. 1994; Nijsen et al. 1998a,b).

\section{METHODS}

\section{Animals and Housing}

Naive male albino Wistar rats (U:WU) weighing 250-300 $\mathrm{g}$ at the beginning of the experiments were used. Rats were housed individually in Macrolon cages $(23 \times 17 \times$ $14 \mathrm{~cm}$ ) containing a layer of woodshavings under conditions of constant ambient temperature $\left(21 \pm 1^{\circ} \mathrm{C}\right)$, constant humidity, and light/dark rhythm (with lights on from 7 A.M. to 7 P.M.). After surgery, the animals were housed individually in Plexiglas cages $(25 \times 25 \times 40 \mathrm{~cm})$ under presurgical conditions. Food (complete laboratory chow; Hope Farms, Woerden, The Netherlands) and water were accessible ad libitum throughout the experiment.

\section{Experimental Design}

Rats were surgically equipped with a telemetric device to study HR, PQ interval, and gross activity and with a cannula in the bed nucleus of the stria terminalis for infusions. They were allowed to recover from surgery for 10 days in the experimental room. During the recovery period the animals were handled daily for weighing and habituation purposes, and accustomed to central infusion procedure (twice before the experiment). Infusions were performed stress-free in resting rats by a long-line technique. All experiments were performed during the light phase of the circadian cycle between 9 A.M. and 1 P.M. After the experiment, all rats were killed by an overdose $(0.5 \mathrm{ml})$ of pentobarbital $(160 \mathrm{mg} / \mathrm{ml})$, dissected, and macroscopically inspected for infections. In none of the animals were any signs of infection found. The position of the cannula was checked microscopically.

The experiments were approved by the ethical committee for animal experimentation of the Medical Faculty, Utrecht University, The Netherlands. 
Experiment 1: Effect of CRH on HR, PQ Interval, and Gross Activity. Rats were infused with $0.2 \mu \mathrm{g}$ CRH in a volume of $0.6 \mu l$ (Lee and Davis 1997) into the medial part of the BNST to determine the role of the CRH system in this brain area in cardiac and behavioral changes. Baseline HR, PQ interval, and gross activity of individual, single-housed rats were telemetrically recorded from $t=-30$ to 0 min under resting conditions in the home cage. Subsequently, rats were infused with saline $(n=10)$ or CRH $(n=14)$ from $t=0$ to $6 \mathrm{~min}$ in their home cages. HR, PQ interval, and gross activity were recorded from $t=0$ to $60 \mathrm{~min}$. Throughout the experiment, rats remained in their home cages.

Experiment 2: Effect of $\alpha \mathrm{CRH}$ on Conditioned FearInduced Cardiac and Behavioral Responses. Rats were infused with $5 \mu \mathrm{g} \alpha \mathrm{hCRH}$ (a non-selective CRH antagonist) in a volume of $0.6 \mu l$ (Lee and Davis 1997) into the medial part of the BNST to study the role of the CRH system in this brain area in cardiac and behavioral responses to conditioned fear.

For the conditioned fear model, a $30 \times 32.5 \times 38.5$ $\mathrm{cm}$ shock box was used, with stainless steel walls, a Plexiglas door, and a grid floor made of $2.5 \mathrm{~mm}$ brass rods spaced $1.0 \mathrm{~cm}$ apart. On Day 1 of the experiment, 24 rats were transferred one by one to a novel shock box where they received $5 \times 0.5 \mathrm{~mA} \times 3$ sec footshocks during $10 \mathrm{~min}$ given at random intervals starting $30 \mathrm{sec}$ after entry. Subsequently, rats were returned to their home cages. On Day 2, baseline HR, PQ interval, and gross activity of rats were recorded in the home cage from $t=-45$ to -15 min under resting conditions and then rats were infused with saline $(n=11)$ or $\alpha$ hCRH $(n=13)$ from $t=-15$ to $-9 \mathrm{~min}$. At $\mathrm{t}=0 \mathrm{~min}$ the procedure from Day 1 was repeated, except that none of the animals was shocked (conditioned fear). HR, PQ interval, and gross activity were recorded from $t=-15$ to $60 \mathrm{~min}$ (post treatment).

\section{Surgery}

Rats were equipped with telemetric devices to study HR, PQ interval, and gross activity and received a guide cannula implanted into the medial part of the BNST for central infusions. Operations were performed under fentanyl/fluanisone anesthesia (Hypnorm ${ }^{\circledR}$; Janssen Pharmaceutica, Beerse, Belgium; $0.1 \mathrm{ml} / 100 \mathrm{~g}$ body weight (BW), intramuscular) and Midazolam hydrochloride (Dormicum ${ }^{\circledR}$; Hoffman-LaRoche, Mijdrecht, The Netherlands; $0.1 \mathrm{ml}$, intraperitoneally) as a muscle relaxant. Before the muscle relaxant was injected, the analgesic effect of fentanyl anesthesia was tested by checking for the absence of its pedal and cornea reflexes. Total absence of the pain response typically appeared after $10 \mathrm{~min}$ and then the muscle relaxant was injected. Surgery was performed under sterile condi- tions in a laminar flow cabinet to minimize risk of infection.

A telemetric transmitter to record gross activity, $\mathrm{HR}$, and PQ interval was implanted in the abdominal cavity according to the procedure described by Nijsen et al. (1998b). Briefly, a small longitudinal incision was made on the linea alba at the anterior of the abdomen. The transmitter was placed in the abdominal cavity. Two electrodes originate from the top of the transmitter, one of which was fixed to the dorsal surface of the xiphoid and the other pushed under the $\mathrm{m}$. sternohyoideus and then along the trachea into the anterior mediastinum. After implantation of a telemetric transmitter, the rats received a guide cannula in the medial part of the BNST. This cannula was implanted according to the stereotaxic atlas of Paxinos and Watson (1986): AP -0.4, L 1.25 , and $\mathrm{V}-7 \mathrm{~mm}$ from the bregma and consisted of a titanium needle (outer diameter (o.d.) $0.4 \mathrm{~mm}$, inner diameter (i.d.) $0.2 \mathrm{~mm}$ ) closed by a tungsten stylet. Postoperatively, the animals received $0.1 \mathrm{mg} / \mathrm{kg}$ of the long-acting opiate analgesic Buprenorfine hydrochloride (Temgesic ${ }^{\circledR}$; Reckitt \& Colman, Kingston-uponHull, UK; $0.1 \mathrm{ml}$, s.c.).

\section{Telemetry}

The telemetry consisted of small wireless transmitters, model TA11CTA-F40 (Data Sciences, Inc., St. Paul, MN, USA), and receivers, model RLA1020 (Data Sciences, Inc.). Digital data, ECGs and gross activity, were transmitted from the receiver to a DataQuest IV data acquisition system (Data Sciences, Inc.). In Experiment 1, 10sec sampling periods were used with intervals of $5 \mathrm{~min}$ to register ECG recordings and gross activity in the home cage. In Experiment 2, 10-sec sampling periods were used with intervals of $1 \mathrm{~min}$ to record ECG recordings and gross activity before and during conditioned fear. After conditioned fear, 10-sec sampling periods with intervals of $5 \mathrm{~min}$ were used. Data at 15-min intervals instead of $5 \mathrm{~min}$ are presented after conditioned fear (post-stress).

Gross activity was monitored by digital pulses that indicate the occurrence of an event of movement activity. The rate at which the events were recorded for changes was $64 \mathrm{~Hz}$. These pulses were counted by the DataQuest IV system and totaled over the 10 -sec period. Then the system scaled the raw value to correspond to counts per min. Mean HR was automatically calculated from ECGs by the DataQuest IV data acquisition system. The PQ interval is defined as the interval between the beginning of the $P$ wave and the beginning of the QRS complex of the ECG, and mainly represents the so-called atrioventricular conduction time. Elongation of the PQ interval can be caused by an increase in vagal and/or a decrease in sympathetic outflow (Su- 
zuki et al. 1991; Penz et al. 1992; Levy and Zieske 1969; Croiset et al. 1994). PQ intervals were automatically analyzed from 10-sec ECG recordings and were averaged by a special software program, PhysioStat PS1000 (Data Sciences, Inc.).

\section{Infusion Procedure}

One hour prior to baseline telemetric measurements, rats were connected to a long $(1.5 \mathrm{~m})$ fused-silica line (i.d. $75 \mu \mathrm{m}$, o.d. $150 \mu \mathrm{m}$; Composite Metal Services LTD, Hallow, United Kingdom), guided by a polyethylene tube (i.d. $0.28 \mathrm{~mm}$, o.d. $0.61 \mathrm{~mm}$; Portex, Hythe, Kent, United Kingdom), for stress-free infusion in the BNST. The fused-silica line was inserted into the guide cannula until the tip of the fused-silica line was placed 1 $\mathrm{mm}$ beneath the tip of the guide cannula. The other end of the long-line was attached to a syringe in a microinfusion pump (Harvard Apparatus, Inc., Massachusetts, USA). Central infusions were performed at $0.6 \mu \mathrm{l} / 6$ min. During central infusions all rats were asleep. No $\mathrm{HR}$, gross activity, or PQ interval responses were seen in rats infused with saline, indicating that our long-line infusion technique is stress-free indeed.

\section{Drug Treatment}

Corticotropin-releasing hormone $(\mathrm{hCRH}(1-41))$ was obtained from Peninsula, Belmont, CA, USA and the nonselective CRH antagonists, $\alpha$-helical CRH(9-41) ( $\alpha$ h$\mathrm{CRH}$ ) from Bachem Feinchemikalien AG, Bubendorf, Switzerland. The drugs were dissolved in saline prior to use.

\section{Position of the Guide Cannula}

After the experiment the brains of the rats were dissected, fixed in a solution of formaldehyde $(4 \%)$, and cryoprotected with $25 \%$ sucrose in phosphate buffer overnight. Sections of the brain $(25 \mu \mathrm{m})$ were made on a cryostat and the slices were immediately checked microscopically for the position of the cannula tract. The examination of the cannula placements was performed by an experimenter blinded to the physiological data.

\section{Statistical Analysis}

HR (beats/min), PQ interval (msec), and gross activity (counts/min) are presented as mean changes ( \pm SEM) in comparison to baseline. Baseline levels were measured over a 30-min period and averaged. These mean baseline levels of the treatment groups were compared by a two-tailed Student t-test. After drug infusion, all data were analyzed by a two-factor Multivariate Analysis of Variance (MANOVA) with repeated measures, with one between-subjects factor (treatment) and one repeated measures within-subjects factor (time). The treatment factor had two levels (CRH or $\alpha \mathrm{hCRH}$ and saline) and the time factor had 12 levels (Experiment 1) or 10 levels (during (from $t=0$ to $10 \mathrm{~min}$ ) and after (from $\mathrm{t}=15$ to $60 \mathrm{~min}$ ) conditioned fear in Experiment 2). $P$-values of $<.05$ were considered significant.

Because of insufficient quality of the telemetric signal, the following data had to be excluded from further analysis: the PQ interval of 1 saline rat (Figure 2B) and 1 $\alpha \mathrm{hCRH}$ rat (Figure $3 \mathrm{~B}$ ).

\section{RESULTS}

\section{Experiment 1: Effect of CRH on HR, PQ Interval and} Gross Activity Under Resting Conditions

$\mathrm{CRH}$ or saline was infused in the medial BNST in groups of rats under resting conditions to study the cardiac and behavioral effects of exogenous CRH.

Position of the Guide Cannula. After the experiment, the position of the cannula was checked microscopically. Figure 1 shows a schematic drawing of the localization of the guide cannula, placed in the medial BNST. In one SAL rat, the cannula was located in the fornix, in three SAL rats, in the septohypothalamic nucleus, in two CRH rats, in the anterior commissure, in two CRH rats, in the septohypothalamic nucleus, and in one CRH rat, in the lateral septum. The results of these rats were excluded from the data as shown in the present study. The results of the five excluded $\mathrm{CRH}$ rats were statistically analyzed as follows. The HR, PQ, and gross activity response to $\mathrm{CRH}$ in these animals was an-

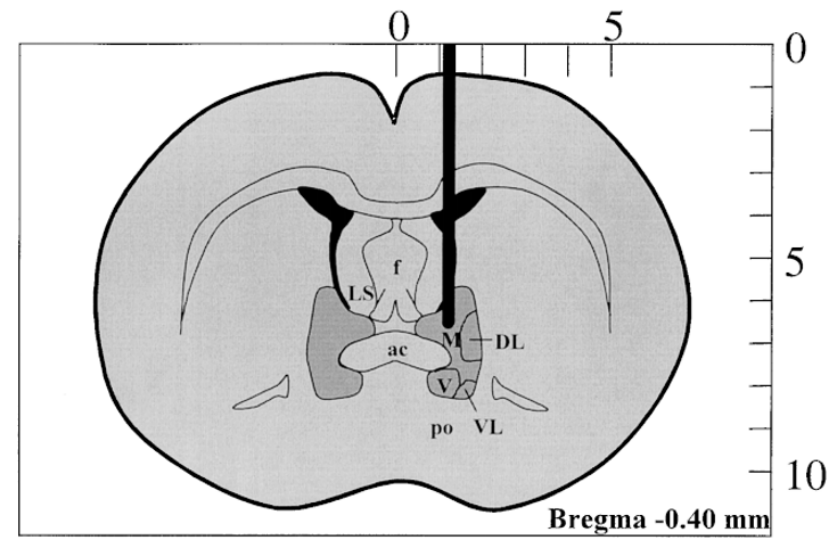

Figure 1. Schematic drawing of a coronal section showing the localization of the guide cannula in the medial bed nucleus of the stria terminalis (BNST). The AP distance is given in $\mathrm{mm}$ respective to the bregma. Abbreviations: LS, lateral septum; po, preoptic area; $\mathrm{f}$, fornix; ac, anterior commissure; $\mathrm{M}$, medial BNST; V, ventral BNST; DL, dorsolateral BNST; VL vetrolateral BNST. 
alyzed in comparison to the saline rats $(n=6)$, which had a cannula in the medial BNST. MANOVA did not reveal significant treatment or time effects of CRH on any of the measured parameters (data not shown).

HR. Mean baseline HR levels prior to treatment were $331 \pm 8$ beats $/ \mathrm{min}$ in the saline group (SAL) and $333 \pm$
7 beats/min in the CRH group. Baseline HR was not significantly different between the two groups of rats. CRH-induced HR responses are shown in Figure 2A. $\mathrm{CRH}$ treatment enhanced mean HR (treatment effect: $\mathrm{F}(1,13)=44.9, p<.001$; treatment by time interaction: $\mathrm{F}(11,143)=8.0, p<.001)$. MANOVA also revealed a significant time effect $(\mathrm{F}(11,143)=6.6, p<.001)$. Figure
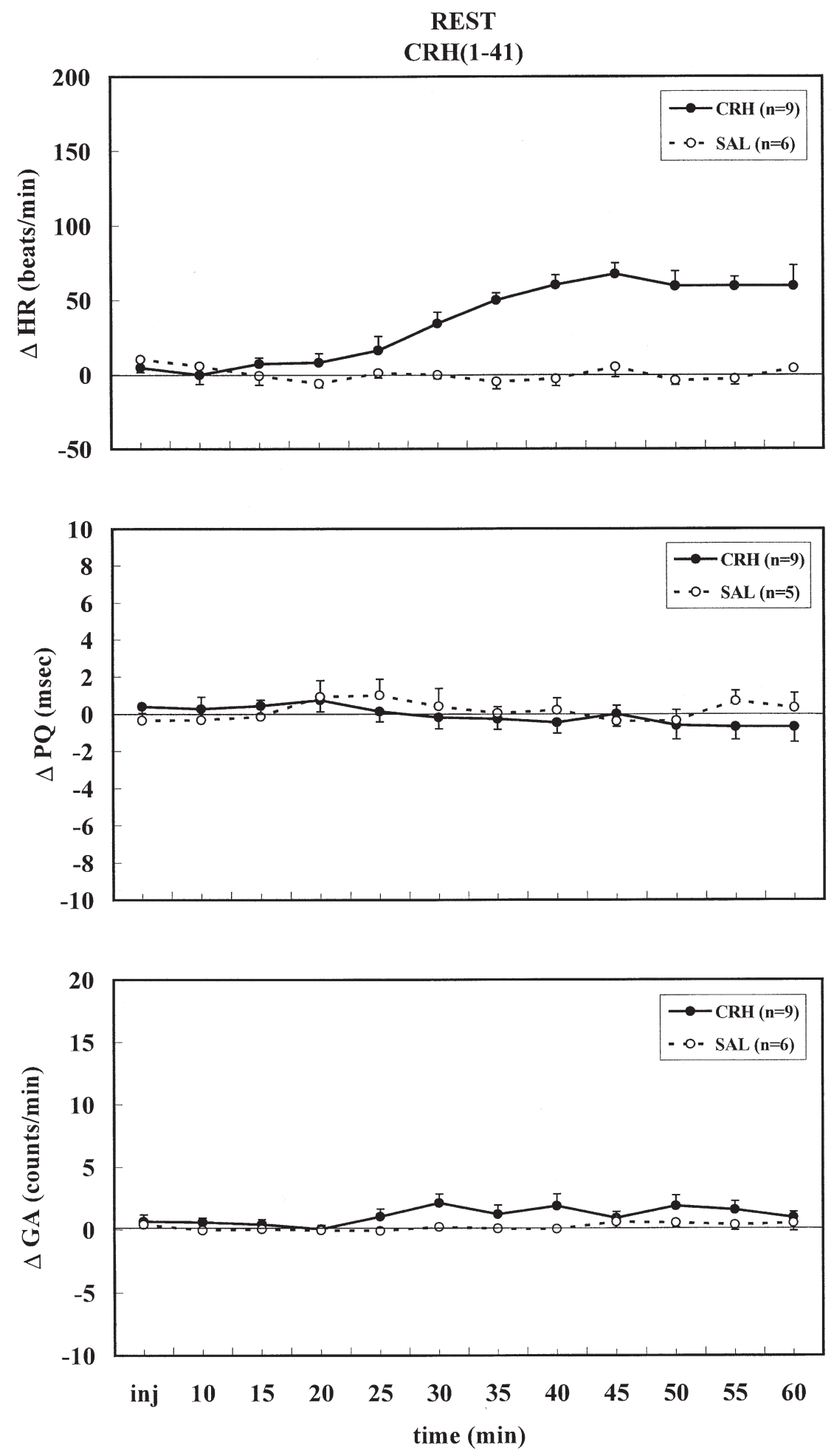

Figure 2. Changes versus baseline in heart rate (HR) (A), PQ interval (B), and gross activity (GA) (C) in CRHtreated rats $(\mathrm{CRH})$ or saline-treated rats (SAL) in their home cage under resting conditions. CRH $(0.2 \mu \mathrm{g} / 0.6$ $\mu \mathrm{l}$ ) or saline was infused icv from $t=0$ to $6 \mathrm{~min}$ (inf). Data are presented as mean \pm S.E.M. 
2A shows that the CRH-induced increase in HR developed after approximately $15 \mathrm{~min}$.

$P Q$ Interval. Mean baseline $\mathrm{PQ}$ interval prior to treatment was $56 \pm 2 \mathrm{msec}$ in the SAL group and $53 \pm 1$ msec in the CRH group. Baseline PQ interval was not significantly different between the two groups of rats. $\mathrm{CRH}$ and saline infusion had no significant treatment, time, or treatment by time interaction effect on PQ (Figure $2 B$ ).

Gross Activity. Mean baseline gross activity levels prior to treatment were $0.2 \pm 0.2$ counts $/ \mathrm{min}$ in the SAL group and $0.1 \pm 0.1$ counts $/ \mathrm{min}$ in the $\mathrm{CRH}$ group. Baseline gross activity was not significantly different between the two groups of rats. CRH-induced gross activity responses are shown in Figure 2C. CRH treatment enhanced mean gross activity (treatment effect: $\mathrm{F}(1,13)=8.3, p<.05)$. Figure $2 \mathrm{C}$ shows that this slight increase in gross activity developed after approximately $25 \mathrm{~min}$.

\section{Experiment 2: Effect of $\alpha$ hCRH on Conditioned Fear-Induced Cardiac and Behavioral Responses}

$\alpha \mathrm{hCRH}$ was infused in rats before conditioned fear to study the role of the endogenous $\mathrm{CRH}$ in the medial BNST in stress-induced cardiac and behavioral responses. No significant time or treatment effects on HR, $P Q$ interval, and gross activity were found during the 50-min period after conditioned fear exposure (poststress).

Position of the Guide Cannula. After the experiment, the position of the cannula was checked microscopically. In one SAL rat, the cannula was located in the septohypothalamic nucleus, in three $\alpha \mathrm{hCRH}$ rats, in the septohypothalamic nucleus, and in one $\alpha \mathrm{hCRH}$ rat, in the lateral septum. The results of these rats were excluded from the data as presented in the present study. The results of the four excluded $\alpha \mathrm{hCRH}$ rats were statistically analyzed as follows. The $\mathrm{HR}, \mathrm{PQ}$, and gross activity response to $\alpha \mathrm{hCRH}$ in these animals was analyzed in comparison to the saline rats $(n=10)$, which had a cannula in the medial BNST. MANOVA did not reveal significant treatment or time effects of $\alpha \mathrm{hCRH}$ on any of the measured parameters (data not shown).

HR. Mean baseline HR levels prior to drug treatment did not differ between the groups ( $348 \pm 9$ beats/min in the SAL group and $352 \pm 4$ beats/min in the $\alpha \mathrm{hCRH}$ group). The changes in mean HR in saline and $\alpha$ hCRH rats during conditioned fear are depicted in Figure 3A. Conditioned fear induced a tachycardiac response in both groups. In time, HR increased during the 10-min conditioned fear exposure in both groups of rats (time effect: $\mathrm{F}(9,153)=23.0, p<.001) . \alpha \mathrm{hCRH}$ treatment en- hanced the conditioned fear-induced tachycardia (treatment effect: $\mathrm{F}(1,17)=5.5, p<.05)$.

$P Q$ Interval. Mean baseline $P Q$ interval prior to drug treatment was similar in the SAL and $\alpha$ CRH group (54 \pm 2 and $53 \pm 1 \mathrm{msec}$, respectively).

Figure 3B depicts the conditioned fear-induced changes in PQ interval. Conditioned fear induced an increase in PQ interval. In time, the PQ interval declined significantly during conditioned fear in both groups (time effect: $(\mathrm{F}(9,144)=20.5, p<.001)$. $\alpha$ hCRH treatment reduced the conditioned fear-induced increase in PQ interval (treatment effect: $\mathrm{F}(1,16)=4.2, p<.05$ ).

Gross Activity. Mean baseline gross activity levels prior to drug treatment were $0.1 \pm 0.1$ counts $/ \mathrm{min}$ in the SAL group and $0.3 \pm 0.1$ counts $/ \mathrm{min}$ in the $\alpha \mathrm{hCRH}$ group. Baseline gross activity was not significantly different between the two groups of rats.

Visual observation indicated that all rats, irrespective of treatment, displayed freezing behavior during the 10-min conditioned fear exposure. Figure 3C shows the conditioned fear-induced gross activity responses in saline and $\alpha \mathrm{hCRH}$-treated rats. In time, gross activity increased significantly during conditioned fear in both groups (time effect: $F(9,153)=3.4, p<.001)$. $\alpha$ hCRH treatment increased gross activity during conditioned fear (treatment effect: $\mathrm{F}(1,17)=10.0, p<.01$; treatment by time interaction: $\mathrm{F}(9,153)=2.0, p<.05)$.

\section{DISCUSSION}

In this study, it was found that infusion of CRH in the medial part of the BNST of freely moving rats under resting conditions increased $\mathrm{HR}$, whereas the PQ interval remained unaffected, indicating that $C R H$ in the medial BNST activates both the sympathetic and vagal cardiac system. CRH induced a slight increase in gross activity which succeeded the tachycardiac response, indicating that the HR response was not a consequence of increased locomotor activity, but likely a direct effect of $\mathrm{CRH}$. Infusion of $\alpha \mathrm{hCRH}$, a non-selective CRH1 and $\mathrm{CRH} 2$ receptor antagonist, prior to conditioned fear reduced the PQ response, and potentiated the tachycardia induced by emotional stress. Taken together, these results show that CRH administration in the medial BNST activates both the sympathetic and vagal cardiac pathways under resting conditions, whereas endogenous CRH in this area contributes to the emotional stress-induced vagal response in rats.

Administration of $\mathrm{CRH}$ in the medial part of the BNST resulted in a significant increase in HR and significant but slight increase in gross activity in conscious rats under resting conditions, whereas infusion of CRH just outside the BNST showed no significant effect on 

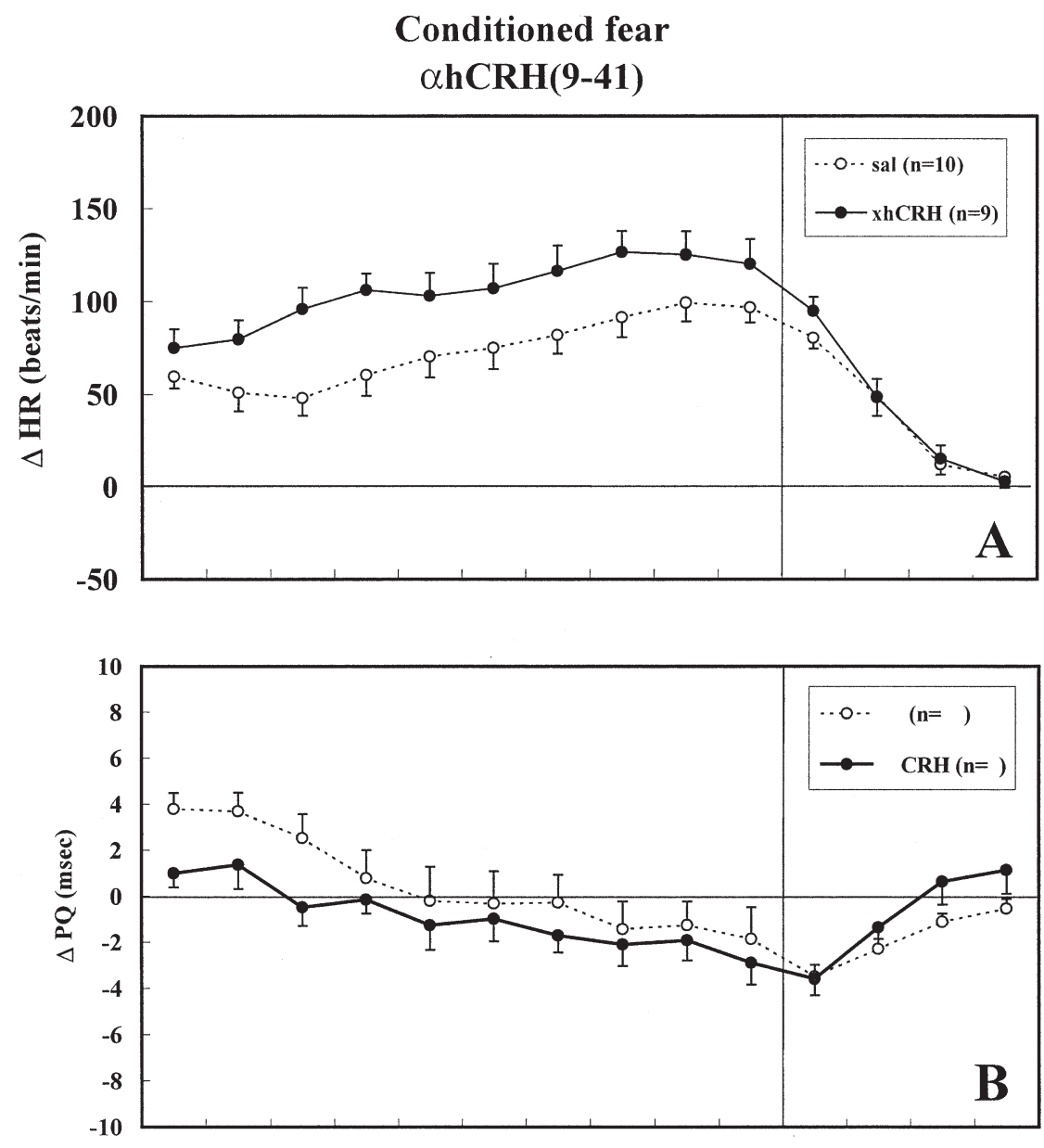

Figure 3. Changes versus baseline in heart rate (HR) (A), PQ interval (B), and gross activity (GA) (C) in $\alpha$ hCRHtreated rats $(\mathrm{xhCRH})$ or saline-treated rats (SAL) during and after 10-min conditioned fear. $\alpha$ hCRH $(5 \mu \mathrm{g} / 0.6 \mu \mathrm{l})$ or saline was infused icv from $t=-15$ to $-9 \mathrm{~min}$. The vertical line marks the end of conditioned fear. Data are presented as mean \pm S.E.M.

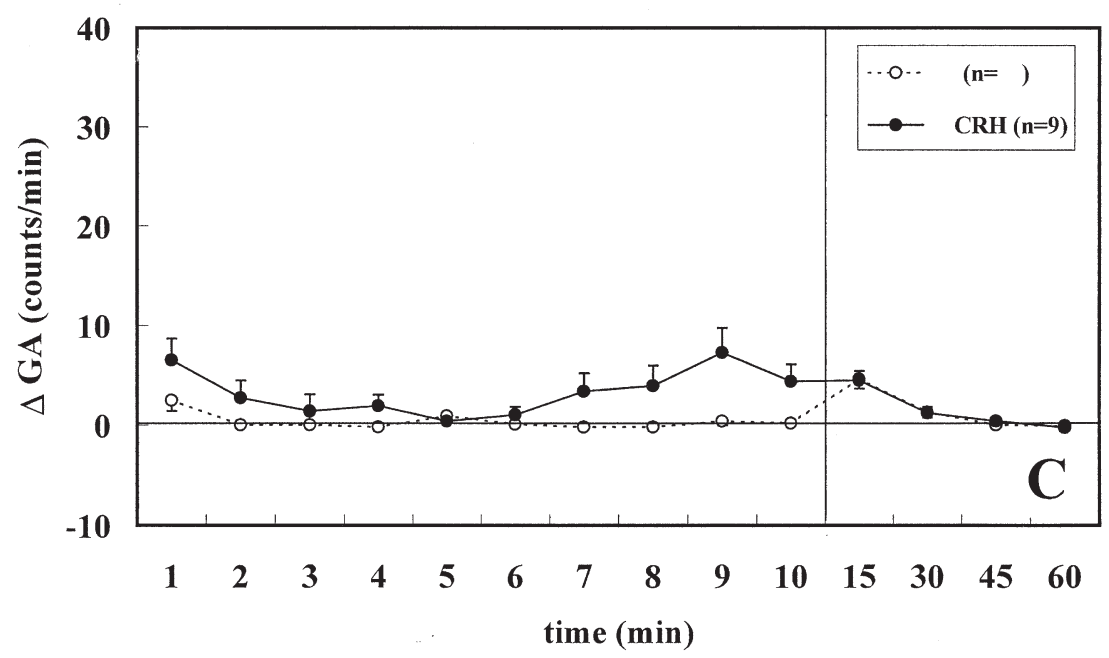

HR or gross activity. A similar increase in HR, but a more pronounced increase in locomotor activity was found in previous studies, in which CRH was infused icv in conscious rats under resting conditions (Morimoto et al. 1993; Nijsen et al. 2000b). Therefore, the data suggest that CRH signalling in the medial BNST plays a major role in the central regulation of $\mathrm{HR}$, but is of less importance for modulation of locomotor activity. The present data further show that the increase in gross activity follows the tachycardiac response with some delay. This indicates that the HR response was not a consequence of the increase in locomotor activity, but rather a direct effect of CRH action in the BNST.

Previously, we and others have found that icv CRH- 
induced tachycardiac responses are associated with increased plasma NE and E levels, indicating that exogenous CRH can activate the SNS (Brown et al. 1982; Korte et al. 1993; Nijsen et al. 2000a). In the present study, the contribution of vagal activity in CRH-induced cardiac responses was determined by the use of the PQ interval. Vagal activation elongates, whereas sympathetic activation shortens the PQ interval (Levy and Zieske 1969; Croiset et al. 1994). If the CRH-induced tachycardia in the present study would have been the result of sympathetic activation only, one would have expected a decrease of the PQ interval. However, the PQ interval remained at baseline levels, which suggests that besides the sympathetic, also the vagal cardiac outflow had been activated.

The present findings confirm those of a previous study showing that conditioned fear induces freezing behavior associated with an increase in HR and PQ interval (Nijsen et al. 1998b). From that study it was concluded that the conditioned fear-induced increase in HR is a result of coactivation of the sympathetic and vagal cardiac outflow. Evidence for sympathetic activation was provided by the enhancement of plasma NE and $\mathrm{E}$ during conditioned fear. Vagal cardiac activation was shown by the conditioned fear-induced elongation of the PQ interval, which was completely abolished by pre-treatment of atropine methylnitrate, a peripherally acting muscarinic antagonist. In the present study, the conditioned fear-induced PQ response was reduced by $\alpha \mathrm{hCRH}$ treatment in the medial BNST as compared to saline-treated rats, whereas the conditioned fear-induced tachycardia was enhanced. Administration of $\alpha \mathrm{hCRH}$ just outside the BNST showed no effect on the conditioned fear-induced increase in HR or PQ interval. The effects of $\alpha \mathrm{hCRH}$ in the medial BNST can be explained by sympathetic activation or vagal withdrawal. Conversely, endogenous $\mathrm{CRH}$, released in the medial BNST due to emotional stress, might induce vagal activation or inhibition of sympathetic cardiac activity. The latter mechanism is unlikely as exogenous $\mathrm{CRH}$ applied in the medial BNST enhanced rather than reduced sympathetic cardiac activity. Thus, CRH signalling in the medial BNST most likely contributes to the cardiac stress response by vagal activation.

The conditioned fear-induced freezing response was reduced by $\alpha \mathrm{hCRH}$ treatment as compared to salinetreated rats. This effect started somewhat later than the increase in HR response. This indicates that the HR response was not a consequence of increased locomotor activity, but likely a direct effect of CRH action in the BNST.

In a previous study, we showed that $\alpha \mathrm{hCRH}$ administered icv reduced the conditioned fear-induced tachycardiac response, potentiated the increase in PQ interval and tended to prolong the freezing response (Nijsen et al., submitted for publication). It was concluded that the endogenous CRH system inhibits fear-induced va- gal activation. However, opposite results were found in the present study; CRH signalling in the medial BNST enhanced rather than reduced vagal activity and freezing behavior during emotional stress. It is possible that the site of action of endogenous CRH determines the nature of the autonomic and behavioral responses. Brain site specificity in the neuromodulatory properties of CRH has also been shown by others, who found differential autonomic and behavioral responses depending on the site of administration of CRH in the brain. Diamant and colleagues (1992), for instance, reported that injection of $\mathrm{CRH}$ in the lateral hypothalamic nucleus in rats induced a long-lasting tachycardia and behavioral activation, such as grooming, eating and locomotion in the home cage, whereas the same dose icv only induced grooming behavior and a short-lasting increase in HR.

Infusion of icv CRH enhanced plasma NE, plasma E, HR, and BP (Brown et al. 1982; Brown and Fisher 1985), whereas the same dose in the central amygdaloid nucleus (CeA) only increased plasma NE in rats (Brown and Gray 1988). Another explanation to be considered for the apparent discrepancy in results between the previous icv study and the present study is that $\alpha \mathrm{hCRH}$ in the dose used $(5 \mu \mathrm{g})$ exerted agonistic activity in the medial BNST and thus mimicked CRH signalling. However, Lee and Davis (1997) reported that CRH $(0.2$ $\mu \mathrm{g}$ ) infusion in the medial BNST in rats enhanced stress-induced behavioral responses, which could be blocked by infusion of $5 \mu \mathrm{g} \alpha \mathrm{hCRH}$ in the medial BNST. Moreover, in the present study, $\alpha \mathrm{hCRH}$ only affected stress-induced responses and had no significant effects on HR, PQ interval, and gross activity in the home cage, just after conditioned fear exposure. These findings strongly suggest that $\alpha \mathrm{hCRH}$, in the dose used, did not exert CRH-agonistic activity.

In summary, the present study showed that the CRH system in the medial BNST is involved in stress-induced autonomic and behavioral responses. CRH administration in the medial BNST resulted in sympathetic and vagal cardiac activation, whereas it had less effect on locomotor behavior under resting conditions. Emotional stress-induced CRH signalling in the medial BNST resulted in an increase in vagal cardiac activation and freezing behavior. Further experiments using selective $\mathrm{CRH}$ antagonists are needed to provide more information on the involvement of the CRH type 1 and 2 receptor in these behavioral and autonomic responses.

\section{ACKNOWLEDGMENTS}

The authors thank M. Agterberg, for his skilled technical assistance.

This research was supported by a research grant from the Netherlands Heart Foundation (NR 93.152). 


\section{REFERENCES}

Allen GV, Cechetto DF (1993): Functional and anatomical organization of cardiovascular pressor and depressor sites in the lateral hypothalamic area. II. Ascending projections. J Comp Neurol 330:421-438

Arnold FJ, De Lucas Bueno M, Shiers H, Hancock DC, Evan GI, Herbert J (1992): Expression of c-fos in regions of the basal limbic forebrain following intracerebroventricular corticotropin-releasing factor in unstressed or stressed male rats. Neuroscience 51:377-390

Bonaz B, Tache Y (1994): Induction of Fos immunoreactivity in the rat brain after cold-restraint induced gastric lesions and fecal excretion. Brain Res 652:56-64

Brown MR, Fisher LA, Spiess J, Rivier C, Rivier J, Vale WW (1982): Corticotropin-releasing factor: Actions on the sympathetic nervous system and metabolism. Endocrinology 111:928-931

Brown MR, Fisher LA (1985): Corticotropin-releasing factor: Effects on the autonomic nervous system and visceral systems. Fed Proc 44:243-248

Brown MR, Gray TS (1988): Peptide injections into the amygdala of conscious rats: Effects on blood pressure, heart rate and plasma catecholamines. Regul Pept 21: 95-106

Chalmers DT, Lovenberg TW, De Souza EB (1995): Localization of novel corticotropin-releasing factor receptor (CRF2) mRNA expression to specific subcortical nuclei in rat brain: Comparison with CRF1 receptor mRNA expression. J Neurosci 15:6340-6350

Chappell PB, Smith MA, Kilts CD, Bissette G, Ritchie J, Anderson C, Nemeroff CB (1986): Alterations in corticotropin-releasing factor-like immunoreactivity in discrete rat brain regions after acute and chronic stress. J Neurosci 6:2908-2914

Croiset G, Raats CJI, Nijsen MJMA, Wiegant VM (1994): Differential effects of cholinergic and adrenergic agents on $\mathrm{P}-\mathrm{R}$ and R-R intervals in rat ECG. Neurosci Res Commun 14:75-84

Davis M, Walker DL, Lee Y (1997): Roles of the amygdala and bed nucleus of the stria terminalis in fear and anxiety measured with the acoustic startle reflex. Possible relevance to PTSD. Ann NY Acad Sci 821:305-331

Diamant M, Kashtanov SI, Fodor M, de Wied D (1992): Corticotropin-releasing factor induces differential behavioral and cardiovascular effects after intracerebroventricular and lateral hypotholamic/perifornical injections in rats. Neuroendocrinology 56:750-760

Fisher LA (1993): Central actions of corticotropin-releasing factor on autonomic nervous activity and cardiovascular functioning. Ciba Found Symp 172:243-253

Giancola SB, Roder S, Ciriello J (1993): Contribution of caudal ventrolateral medulla to the cardiovascular responses elicited by activation of bed nucleus of the stria terminalis. Brain Res 606:162-166

Gray TS, Magnuson DJ (1987): Neuropeptide neuronal efferents from the bed nucleus of the stria terminalis and central amygdaloid nucleus to the dorsal vagal complex in the rat. J Comp Neurol 262:365-374

Herman JP, Cullinan WE, Watson SJ (1994): Involvement of the bed nucleus of the stria terminalis in tonic regula- tion of paraventricular hypothalamic CRH and AVP mRNA expression. J Neuroendocrinol 6:433-442

Holstege G, Meiners L, Tan K (1985): Projections of the bed nucleus of the stria terminalis to the mesencephalon, pons, and medulla oblongata in the cat. Exp Brain Res 58:379-391

Hopkins DA (1987): The dorsal motor nucleus of the vagus nerve and the nucleus ambiguus : Structure and connections. In Hainsworth R, McWilliam PN, Mary DASG (eds), Cardiogenic Reflexes. Oxford, Oxford University Press, pp 185-203

Koob GF, Tazi A, Le Moal M, Thatcher-Britton K (1989): Corticotropin-releasing factor, stress and arousal. In Teché Y, Morley JE, Brown MR (eds), Neuropeptides and Stress. New York, Springer, pp 49-60

Korte SM, Bouws GAH, Bohus B (1993): Central actions of corticotropin-releasing hormone $(\mathrm{CRH})$ on behavioral, neuroendocrine, and cardiovascular regulation: Brain corticoid receptor involvement. Horm Behav 27:167-183

Lee Y, Davis M (1997): Role of the hippocampus, the bed nucleus of the stria terminalis, and the amygdala in the excitatory effect of corticotropin-releasing hormone on the acoustic startle reflex. J Neurosci 17:6434-6446

Levy MN, Zieske H (1969): Autonomic control of cardiac pacemaker activity and atrioventricular transmission. J Appl Physiol 27:465-470

Morimoto A, Nakamori T, Morimoto K, Tan N, Murakami N (1993): The central role of corticotrophin-releasing factor (CRF-41) in psychological stress in rats. J Physiol (Lond) 460:221-229

Nijsen MJMA, Croiset G, Diamant M, Broekhoven MH, De Wied D, Wiegant VM (1998a): Vagal activation in novelty-induced tachycardia during the light phase in the rat. Physiol Behav 63:233-239

Nijsen MJMA, Croiset G, Diamant M, Stam R, Delsing D, De Wied D, Wiegant VM (1998b): Conditioned fear-induced tachycardia in the rat; vagal involvement. Eur J Pharmacol 350:211-222

Nijsen MJMA, Croiset G, Diamant M, Stam R, Kamphuis PJ, Bruijnzeel A, De Wied D, Wiegant VM (2000a): Endogenous corticotropin-releasing hormone inhibits conditioned-fear-induced vagal activation in the rat. Eur J Pharmacol 389:89-98

Nijsen MJMA, Croiset G, Stam R, Bruijnzeel A, Diamant M, De Wied D, Wiegant VM (2000b): The role of the CRH type 1 receptor in autonomic responses to corticotropinreleasing hormone in the rat. Neuropsychopharmacology 22:388-399

Onaka T, Yagi K (1998): Role of noradrenergic projections to the bed nucleus of the stria terminalis in neuroendocrine and behavioral responses to fear-related stimuli in rats. Brain Res 788:287-293

Pacak K, Palkovits M, Kopin IJ, Goldstein DS (1995): Stressinduced norepinephrine release in the hypothalamic paraventricular nucleus and pituitary-adrenocortical and sympathoadrenal activity: In vivo microdialysis studies. Front Neuroendocrinol 16:89-150

Paxinos G, Watson C (1986): The Rat Brain in Stereotaxic Coordinates, 2nd ed. San Diego, Academic Press

Penz W, Pugsley M, Hsieh MZ, Walker MJA (1992): A new 
ECG measure (RSh) for detecting possible sodium channel blockade in vivo in rats. J Pharmacol M 27:51-58

Phelix CF, Paull WK (1990): Demonstration of distinct corticotropin releasing factor-containing neuron populations in the bed nucleus of the stria terminalis. A light and electron microscopic immunocytochemical study in the rat. Histochemistry 94:345-364

Sakanaka M, Shibasaki T, Lederis K (1986): Distribution and efferent projections of corticotropin-releasing factor-like immunoreactivity in the rat amygdaloid complex. Brain Res 382:213-238

Song CAI, Earley B, Leonard BE (1995): Behavioral, neurochemical, and immunological responses to CRF administration. In Chrousos GP, McCarty R, Pacák K, Cizza G, Sternberg E, Gold PW, Kvetnansky R (eds), Annals of the New York Academy of Sciences. "Stress: Basic Mechanisms and Clinical Implications". New York, The New York Academy of Sciences New York, pp 55-72

Stoddard SL, Bergdall VK, Townsend DW, Levin BE (1986a):
Plasma catecholamines associated with hypothalamically-elicited defense behavior. Physiol Behav 36:867-873

Stoddard SL, Bergdall VK, Townsend DW, Levin BE (1986b): Plasma catecholamines associated with hypothalamically-elicited flight behavior. Physiol Behav 37:709-715

Suzuki J, Tsubone H, Sugano S (1991): Characteristics of electrocardiograghic changes with some representative antiarrhythmic drugs in adult rats. J Vet Med Sci 53:779-787

Swanson LW, Sawchenko PE, Rivier J, Vale WW (1983): Organization of ovine corticotropin-releasing factor immunoreactive cells and fibers in the rat brain: An immunohistochemical study. Neuroendocrinology 36: 165-186

Valentino RJ, Foote SL (1986): Brain noradrenergic neurons, corticotropin-releasing factor, and stress. In Moody TW (ed), Neural and Endocrine Peptides and Receptors. New York, Plenum Press, pp 101-120 